\title{
What was old .... is new again!
}

\author{
W. Randolph Chitwood, Jr, MD, FACS, FRCS (England)
}

\author{
From the Department of Surgery, East Carolina Heart Institute, Greenville, NC. \\ Disclosures: Author has nothing to disclose with regard to commercial support. \\ Received for publication Aug 15, 2016; accepted for publication Aug 19, 2016; available ahead of print Sept 21, \\ 2016. \\ Address for reprints: W. Randolph Chitwood, Jr, MD, FACS, FRCS (England), 146 East Longmeadow Rd, Green- \\ ville, NC 27858 (E-mail: chitwoodw@ecu.edu). \\ J Thorac Cardiovasc Surg 2016;152:1629-30 \\ 0022-5223/\$36.00 \\ Copyright (C 2016 by The American Association for Thoracic Surgery \\ http://dx.doi.org/10.1016/j.jtcvs.2016.08.027
}

Today, the use of expanded polytetrafluoroethylene (ePTFE) strands to replace either redundant or ruptured chordae tendineae has become a main stay in mitral valve repair. The history of using ePTFE replacement chords, now called neochords, bespeaks an important innovation by surgeons. In 1962 Dr R. W. M. Frater began to experiment and clinically use pericardial strips to replace elongated and/or ruptured chords. ${ }^{1-4}$ His results were good, with several years of durability reported; however, he described to me, "Their use was inconvenient as often many chords had to be replaced."

Other types of suture replacement had been attempted but failed. Carpentier showed that chordal transfer was effective but many surgeons found this technique demanding as often a chord-bearing "donor" leaflet segment was required. In 1986 Vetter and colleagues ${ }^{5}$ presented their experimental studies in which they used ePTFE for chord replacements at a valve meeting in London. At that meeting, Tirone David was impressed by the technique and was the first to implant ePTFE (Gore-Tex) neochords in patients with degenerative mitral valve disease. During the next 10 years, the technique spread from surgeon to surgeon around the world without regulatory approval of any kind. Thereafter, the W. L. Gore \& Associates (Flagstaff, Ariz) gained approval from the Food and Drug Administration in 1996 for use in intracardiac surgery. In 2013 David and colleagues ${ }^{6}$ reported that their 18-year freedom from reoperation was 90\% using ePTFE neochords. Similarly the "Leipzig loop" technique has been shown to have excellent long-term results."

There have been many variations in the use of ePTFE chord implantations for degenerative mitral disease. In the Frater-David, method the PTFE suture is anchored first in the papillary muscle and emerges to be passed twice through the leaflet, looping around the coapting edge. The Leipzig loop technique distributes multiple anchors along the leaflet the edge or just above it. With both techniques, the systolic stress is transferred to individual anchoring points (strain); however, the restoration of coaptation works oppositely to decrease loading stress at each point.

In this issue of the Journal, Sakaguchi and colleagues ${ }^{8}$ present a technique that ostensibly has several advantages over other methods. In 1989, Revuelta and colleagues ${ }^{9}$ described

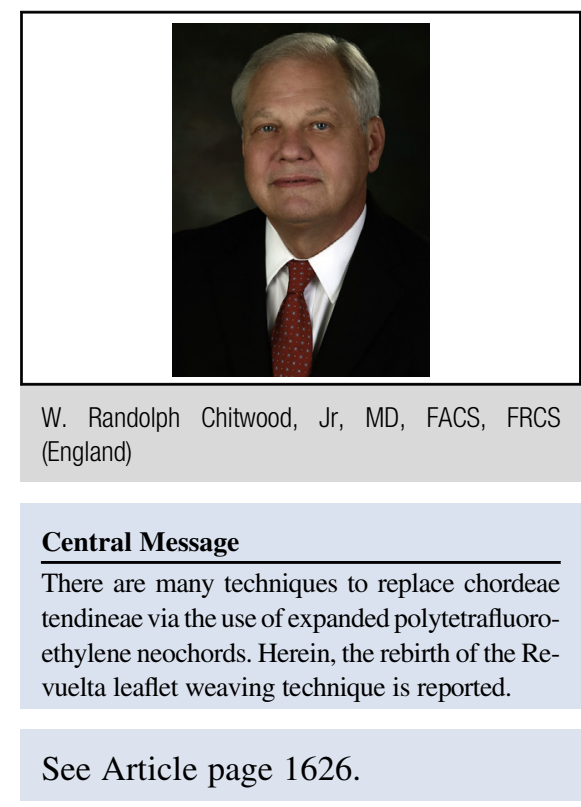

a very similar ePTFE leaflet weaving technique (Figure 1). The only difference in the current paper relates to the suture ends being passed through the annuloplasty ring before tying. By weaving the ePTFE neochord from the edge through the coapting plane and through the annulus, it would seem that the systolic stress is distributed along a broader surface (strain) area than individual point attachments. As the weave acts as sort of a belt, the leaflet may be able to have more parabolic "billowing," rendering less stress with more natural posterior leaflet motion. Lastly, by advancing each suture through the annuloplasty ring, tying without knot slippage may be an advantage to some surgeons. This small series begs these questions but is not large enough nor has enough long-term echo data to absolutely prove these points.

There are concerns with using this technique regarding long-term results. We know that ePTFE usually forms a fibrous capsule in biologic systems and can cause calcification. In fact reoperations have shown that often a neochord is indistinguishable from an adjacent native chord. To this end, how can we be sure that the larger ePTFE surface area woven along the native leaflet will not cause fibrosis or calcification, immobilizing the repaired segment? We have no long-term comparative studies in which so much ePTFE is distributed through the entirety of a leaflet. Nevertheless, the work of Dr Sakaguchi and colleague's does reintroduce an innovative concept expanding the armamentarium of repair techniques. These authors have revived the technique of Revuelta and colleague. What was old is new again! 


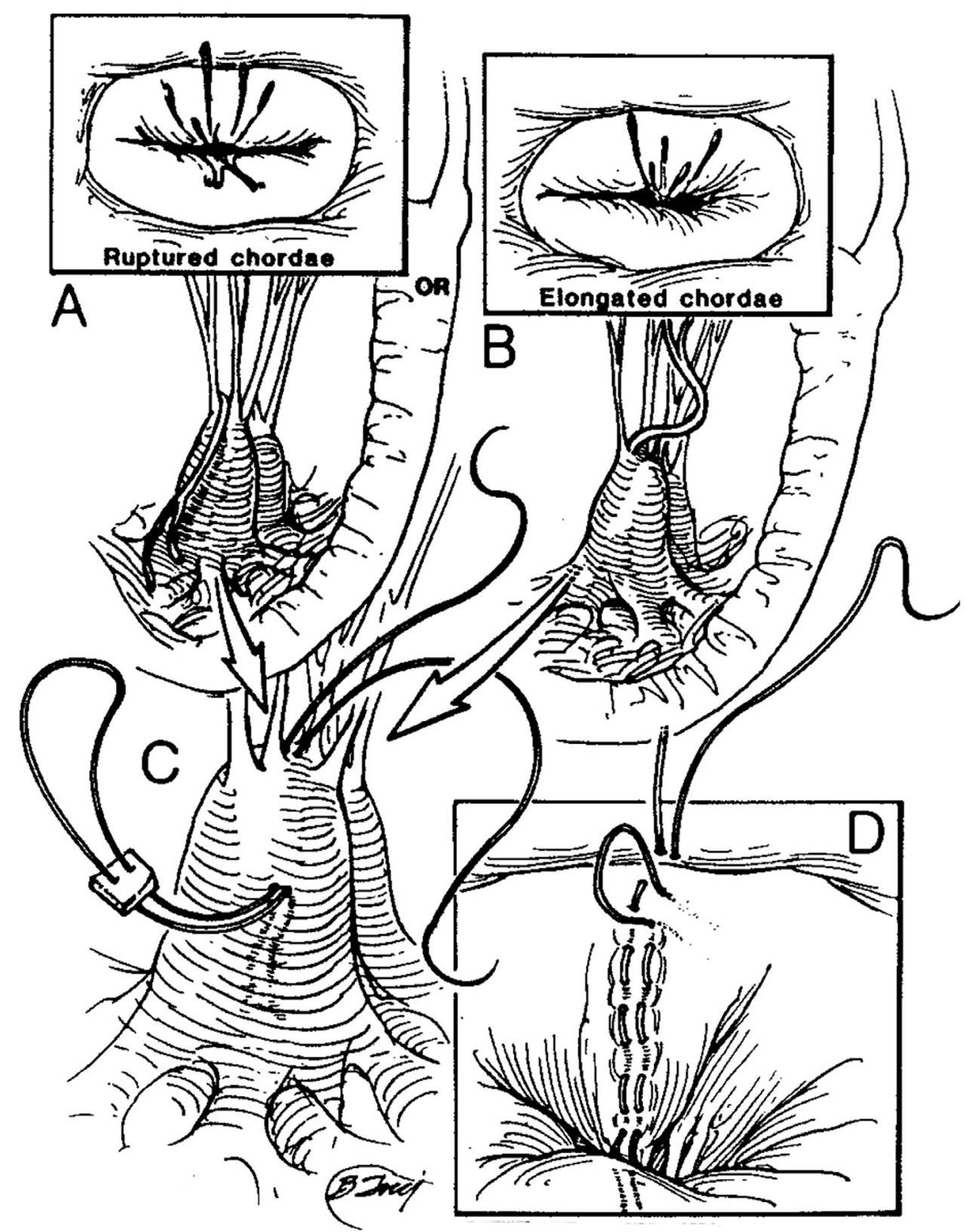

FIGURE 1. The ePTFE leaflet weave repair of Revuelta and colleagues (1989) ${ }^{9}$ : An old technique returns.

Dr R. W. M. Frater was immensely helpful for lending his historical knowledge of ePTFE chordae tendineae replacements.

\section{References}

1. Frater RW. Experimental replacement of parts of the mitral valve with wholly flexible prosthetic cusps and chords. S Afr Med J. 1962;779.

2. Shore DF, Gabbay S, Yellin EL, Frater RW. Degenerative changes in glutaraldehyde-preserved pericardium used for the experimental replacement of anterior chordae of mitral valve. J Cardiovasc Surg (Torino). 1983;24: $132-7$.

3. Frater RW, Gabbay S, Shore D, Factor S, Strorm J. Reproducible replacement of elongated or ruptured mitral valve chordae. Ann Thorac Surg. 1983;35: 14-28.

4. Bortoltti U, Milano AD, Frater RW. Mitral valve repair with artificial chordae. A review of its history, technical details, long-term results, and pathology. Ann Thorac Surg. 2012;93:684-91.
5. Vetter HOBJ, Factor SM, Frater RW. Replacement of chordae tendenae of the mitral valve using the new expanded PTFE suture in sheep. In: Bodnar E, Yacoub M, eds. Biologic and Bioprosthetic Valves. London: Yorke Medical Books; 1986:772-84.

6. David TE, Armstrong S, Ivanov J. Chordal replacement with polytetrafluoroethylene sutures for mitral valve repair: a 25-year experience. J Thorac Cardiovasc Surg. 2013;145:1563-9.

7. von Oppell U, Mohr FW. Chordal replacement for both minimally invasive and conventional mitral valve surgery using premeasured Gore-tex loops. Ann Thorac Surg. 2000;70:2166-8.

8. Sakaguchi T, Totsugawa T, Tamura K, Yoshitaka H. Extended neochord weaving technique for degenerative mitral valve disease. J Thorac Cardiovasc Surg. 2016; 152:1626-8.

9. Revuelta JM, Garcia-Rinaldi R, Gaite L, Val F, Garijo F. Generation of chordae tendineae with polytetrafluoroethylene stents. Results of mitral valve chordal replacement in sheep. J Thorac Cardiovasc Surg. 1989;97:98-103. 